Discourse and Communication for Sustainable Education, vol. 11, no. 1, pp. 134-152, 2020

\title{
University Students' Readiness for Social Activity in Climate Actions
}

\author{
Sari Harmoinen, Katri Koivu, and Leena Pääsky \\ University of Oulu, Oulu, Finland
}

\begin{abstract}
In this study, the authors analyze how students from the University of Oulu $(\mathrm{N}=1585)$ reflect on their possibilities to affect climate matters through social activity. The data was collected with an online survey in the autumn of 2019 and was analyzed with quantitative and qualitative methods. Readiness for climate actions in social activity was moderately low and lower than in other climate actions considered in the survey. The following categories were identified to explain readiness for social activity: Emotional Expressions, Trustworthy Information, Individual Freedom, Societal Responsibility, and Us Against the World-mindset. Some of the possibilities for climate actions suggested by students include developing and exporting Finnish innovations and expertise, leading by example, receiving and distributing reliable information, making decisions and regulations on a societal level, providing economical support for environmental organizations, and affecting personal actions.
\end{abstract}

Key words: climate change, attitude, social activity, responsibility, affection, actuation

\section{Introduction}

Climate change is a severe problem and a complex and systemic challenge (Incropera, 2015). From an individual's perspective, the transformation of attitudes and actions towards a more climate-friendly outlook is a difficult matter. Even when one already prefers pro-climate choices, there is the struggle of how to share one's own ideas and whether stressing them is a sensible line of action. In the media climate activism has become the face of Greta Thunberg, but how many of us are ready for the same level of commitment? Do individual's actions need to affect the choices of others? This paper describes the willingness and views of students at the University of Oulu in Finland about taking part in climate action.

The endeavour to make one's own conclusions regarding climate change, and decisions on how to act on them, is often faced with an amalgam of emotional response and reliance on knowledge (Ojala, 2013a, b; Pihkala, 2017b). Fact-based perspective assists in the comparison of different impressions of climate change as well as in the reflection of required actions, but it does not erase the necessity of choice between various options. The description of a phenomenon does not contain a prescription (Schlott- 
mann, 2012). Science, no matter how rigorous, can only be an informant in the decisionmaking process (Holsman, 2001). Consequently, scientific, environmental matters are also value issues (Schlottmann, 2012).

Values are relatively stable commitments that give people normative grounds for the promotion of their aims (Salonen \& Konkka, 2015), whereas attitudes are lasting feelings regarding an object, issue or person (Kollmus \& Agyeman, 2002). For Kollmus and Agyeman (2002), environmental knowledge, attitudes, values, and emotional involvement form "pro-environmental consciousness" (p. 256) and that is a part of a larger personal setting that contains value systems and personality traits. In addition to internal factors, pro-environmental behaviour is influenced by external factors such as economic situations and socio-political matters (Kollmus \& Agyeman, 2002). Media can also affect higher education students' perceptions on environmental issues (Keinonen et al., 2016).

Behaviour is not always in parallel with values (Salonen, 2019), and there is a welldocumented gap between environmental knowledge or awareness and pro-environmental action (Kollmuss \& Agyeman, 2002). Emphasizing the role of habits, Kollmuss and Agyeman (2002) have explained that people may even be willing to make changes in their behaviour, yet do not do so, because there is not enough persistence in practicing new actions for them to become habits. The other way around, according to Klöcker, Matthies, and Hunecke (2003), a strong habit can prevent norm activation. In consumer behaviour, people seek to maintain a normal, conventional level of consumption that enables societal belonging and it is culturally associated with positive meanings (Häikiö, 2012).

Salonen and Åhlberg (2012) have described sustainability as "an existential challenge" (p. 21) that is connected to beliefs regarding right and wrong behaviour. The earlier engagements in a place in the world conditions ethical understanding (Bonnett, 2012). People are beings, who are contextually grounded and it is not possible to separate "being" from "here" (Sauvé, 2009, p. 325). According to Massey (2004), the Western geography of responsibility and care resembles a Russian doll set: People care first for those who are nearest, for instance, locals before other people of the same nation. One reason behind this is the tendency to connect local places with genuine meaning, while leaving global space as "the abstract outside" (p. 9).

However, the mutual dependency between people around the world covers the entire planet (Salonen \& Åhlberg, 2012), of which the coronavirus pandemic is a case in point. As Schlottmann (2012) has described, the globalized world contains big conflicts between different scales of rights and responsibilities. Caring for one's own community locally, but not giving money as a global citizen to prevent a famine [or currently, the virus from spreading], is an example of ethical action on one scale but unethical on the other. According to Gardiner (2006) the climate change problem is "the perfect moral storm" (p. 398), because it consists of elements such as the global and intergenerational dispersion of causes and consequences that induce considerable impediments to people's ability to make difficult decisions needed to tackle it.

It is challenging to concern oneself with people who live faraway, because the connection between an act and the consequences it generates elsewhere is rarely obvious (Kronlid \& Öhman, 2013). Additionally, as noted by Schlottmann (2012), climate change brings out ethical challenges, because it is connected to unsettled issues in moral philo- 
sophy, for instance: What is the responsibility of people for probabilistic and distant (in space and in time) consequences? Wals (2020) has remarked that there is no automatic consensus on the importance of caring for all people and the planet. The right scale of ethical action: global, national, or local is a contested matter (Schlottmann, 2012).

According to UNESCO (2002), sustainable development necessitates the acknowledgement of interdependencies between social, political, economic and environmental objectives. The Division for Sustainable Development Goals (DSDG) of the UN DESA offers support and capacity-building regarding the planning of policies connected to the goals. Regarding United Nations' (2012) Framework Convention on Climate Change, the Doha work programme on Article 6 of the Convention recognizes that education aims to advance sustainable development by promoting lifestyle changes and by preparing both individuals and communities for the effects of climate change. As indicated by these UN institutions, decisions concerning development need to be made also on a societal level, and not to be left only as the responsibility of individuals.

Considering education from the perspective of Bildung, a notion that means development as a human (Pikkarainen, 2012), moral achievement (Horlacher, 2016), "the refinement of intellect, sensibility and judgement" (Reichenbach, 2002, p. 409) and that also refers to processes between the self and the world (Kivelä, Siljander, \& Sutinen, 2012), the question is not only about an individual transformation, as the idea is to elevate the entire society through the actions of people (Horlacher, 2016). Bildung is concerned with social transformation that is achieved through the cultivation of individuals (Masschelein \& Ricken, 2003). It is about being willing and able to pose, value, and solve the basic contemporary problems (Volanen, 2012). Sustainability competencies are eventually reflected in the extent that students are able to transform both themselves and their society towards sustainability (Besong \& Holland, 2015).

In a meta-analysis of 128 pro-environmental behaviour research (Hines, Hungerford, \& Tomera, 1987) studies found that knowledge of issues, attitudes, and individual sense of responsibility are associated with responsible pro-environmental behaviour. Lorenzoni, Nicholson-Cole, and Whitmarsh (2007) identified the following individual barriers in engaging with climate change: lack of knowledge, uncertainty and skepticism, distrust in information sources, externalizing responsibility and blame, reliance to technology, perceiving climate change as a distant threat, prioritizing other matters, reluctance to change lifestyle, fatalism, and helplessness. Social barriers were also identified, and they included lack of actions from governments, business, and industries, the free-rider effect, pressure of social norms and expectations, and the lack of enabling initiatives (Lorenzoni et al., 2007).

Emotions affect our behaviour (LeDoux, 2012). Cultural emotional norms affect how emotions regarding climate change are expressed; therefore non-participation in relevant movements can be actively produced in a community (Norgaard, 2006, 2011). Taylor, Dessai, and Bruine de Bruin (2014) have emphasized the need for a countryspecific approach when examining the connection between local weather and the public's beliefs on climate change. Their study also suggested that psychological distancing and concern about climate change can be impacted by highlighting local climate impacts (Taylor, Dessai, \& Bruine de Bruin, 2014). It is also important to consider problems such as climate change using a time scale that enables tackling the problems here and now, instead of residing in frightening future scenarios (Postma \& Smeyers, 2012). 
Grief, loss, sadness, shame, anger, fear, guilt, frustration, overwhelmingness, and despair have all been connected to climate change (Hamilton, 2019). Positive emotions, such as hope, gratitude, and empathy, can also be associated with the matter, but these positive emotions mainly occur when painful emotions are not avoided but rather worked through (Hamilton, 2019). In an American study, global warming as a term aroused negative affective connotations in most respondents (Smith \& Leiserowitz, 2012). Significant degrees of challenging emotions caused by environmental issues can result in climate anxiety (Pihkala, 2019). Taking action has often been seen as the solution for climate anxiety but this also means we need to deal with different kinds of emotions, and these are valuable (Pihkala, 2019).

Instead of not caring, people might, in fact, care too much and resort to psychological defenses or paralyzing anxiety, apathy, and helplessness (Weintrobe, 2013; Pihkala, 2017a). Norgaard (2006) reported from a study done in Norway that people avoid thinking about climate change to avoid feeling the threat to one's existence, to avoid emotions of helplessness and guilt, and to minimize the threat to one's sense of identity. These unpleasant emotions are managed by selective attention: avoiding thinking about them, by shifting attention to positive self-representations, and by framing them in ways that help minimize their power. People also selected what they focused their attention on. This selective perception was used by belittling Norway's role in global warming: "We are so few, it doesn't really matter what we do anyway", conveying both a sense of powerlessness and getting off the hook. Attention was also turned to the USA to deflect Norwegian responsibility: "We are not as bad as they are" (Norgaard, 2006). Norgaard's (2011) study suggests that people's attempts to avoid unpleasant emotions by emotion management can hinder participation in social movements.

According to Smith and Leiserowitz (2014), discrete emotions have a vital role in the public's support for climate change policy; especially the emotions of worry, hope, and interest associated strongly with policy support, while disgust was associated with opposition of these policies. Strongest predictors of risk perception towards climate change are the negative affect and imagery on the subject (Leiserowitz, 2006; Smith \& Leiserowitz, 2012). According to Yang and Kahlor (2013), avoiding additional information on climate change seems to be driven by positive affect, for instance, excitement and hopefulness, while information-seeking is influenced more by negative affect, such as anxiety or depression.

Negative emotions are important to take into consideration because grief and outrage can lead to increased motivation and action (Anspach \& Draguljić, 2019). Salama and Aboukoura (2018) point out that, according to psychological experimental evidence, producing fear by communication is effective in motivating behaviour and changing attitudes. Even though fear as a main message in climate change communication can grab attention, it is usually not what empowers action. There is a notable risk of backfiring, when using deliberate attempts to implant fear or guilt that can hinder engagement in climate change matters (Salama \& Aboukoura, 2018), and this can lead to increased global warming skepticism (Feinberg \& Willer, 2011).

Markowitz and Shariff (2012) identify positive emotional appeals as one of the most promising strategies for climate change communication. They encourage us to motivate action through positive emotions, such as hope, pride and gratitude. Positive emotions do not only guide behaviour in the moment, but, according to the broaden- 
and-build theory, they have long-lasting consequences as the means for individual growth and social connection (Fredrickson, 2001).

Based on this, this is important to discover how youth evaluate their own possibilities to affect and reduce climate change. In this study, the aim is to find out how university students reflect on their possibilities to affect climate matters through social activity. Our research questions are as follows:

1. How ready are university students for social activity in matters regarding climate change?

2. How do students explain their readiness for climate actions in social activity?

3. What kind of opportunities of social activity do they bring up?

\section{The Study}

\section{Data Collection Procedure}

The data collection was carried out at the end of 2019. The survey was sent to all students (aged 19 and up) of the University of Oulu and it received responses from 1684 people, 1585 of whom filled in the survey as students i.e., not staff members. Their answers were included in the analysis. The Webropol survey was modified from a questionnaire created by Tolppanen, Claudelin, and Kang (2020). The survey contained categories regarding transportation, travel, diet and food, consumption and recycling, housing and energy consumption, and social activity. It consisted of background information questions, quantitative questions, where students assessed their readiness for diverse climate actions, as well as open-ended questions, where students could voice their perceptions on each category.

The multiple-choice questions were answered on a Likert scale which ranged from 1-5 (1 = not at all ready, 2 = not very ready, 3 = quite ready, $4=$ very ready, $5=$ I already do this). Number 5 meant that the student already implemented the climate action in their life, representing absolute readiness. In the open-ended questions, the students were given the chance to express their thoughts and ideas freely about different predetermined areas of climate actions.

\section{Method of Data Analysis}

The analysis was executed with a mixed methods research design. The collected quantitative data was analyzed with SPSS. Sum variables were created to represent each of the different areas for climate action readiness. The analysis consisted of examining and comparing key figures and distributions between and within different climate action categories to find out how ready university students were to take climate actions within the determined areas. The examination of the key figures allows the description of the collected data (Metsämuuronen, 2006), which was important because the aim was to perceive how ready students are for climate actions in different categories.

The provision of central tendency with means, medians, and modes produces summary information about the examined items, and the best and most reliable way to describe the data depends on its normality and skewness (Greasley, 2008). Because there is notable skewness, especially in some of the questions that produce the sum variable of 
social activity, both means and medians are presented in this paper. During the analysis, the sum variable was handled both as continuous data and stylised into ordinal data for easier comparison with the original questions measured on a Likert-scale. The results and conclusions made from data are the same, regardless of type of measurement.

After completing the quantitative analysis of the survey, the answers to the openended question in the category for social activity were analyzed. Open-ended questions can be used when there is a need for spontaneous explanations with only few limits for the respondents (Vilkka, 2017). Elo and Kyngäs (2008) suggest the use of inductive content analysis if research involves qualitative content that lacks previous studies or knowledge of the subject is fragmented. Because climate action thematics is still a relatively new topic, we chose an inductive and descriptive approach. Johnston, Rasmusson, Foyil, and Shopland (2017) developed a collective understanding of their research data by identifying themes in the texts both individually and collaboratively as a part of their content analysis process. We worked in a similar manner: the answers to the openended question were first categorized individually by each researcher and after that they were compared and a common coding criteria consisting of five main categories was created and used for the data. Researcher triangulation was actively utilized during the data analysis stage to insure validity of the results.

\section{Research Findings}

The data consisted of 1585 participants (65\% women, $33.5 \%$ men, $1.5 \%$ other). $66.5 \%$ of the respondents were aged 25 or under, $19 \%$ were between the ages of $26-$ 30 , and $14 \%$ were 31 years old or over. After first analyzing the survey as a whole, we decided to concentrate on the category of social activity because of how it stood out from the other categories.

Quantitative analysis revealed that Readiness for Climate Actions in the sum variable of social activity was evaluated lower than in the other categories. This sum variable consisted of five questions (Table 1), and the Chronbach's alpha was 0.868. University students' readiness for climate actions regarding social activity can be considered moderately low $(\mathrm{M}=2.89, \mathrm{SD}=0.97, \mathrm{Mdn}=3, \mathrm{~N}=1585)$, with $33.0 \%$ reporting low readiness, $38.9 \%$ reporting to be quite ready, and $28.2 \%$ reporting high readiness for climate actions in this category.

An Independent Samples T-test (Welch's t-test) was conducted to find out whether there was a significant difference in readiness for social activity between men and women because these categories were large enough for further analysis. The T-test concluded that women $(\mathrm{M}=3.13, \mathrm{SD}=0.87, \mathrm{~N}=1030)$ demonstrated significantly higher readiness for climate actions in social activity than men $(\mathrm{M}=2.43, \mathrm{SD}=0.99$, $\mathrm{N}=532), \mathrm{t}(963.9)=-13.6, \mathrm{p}<0.001, \mathrm{~d}=0.74$.

The reported readiness varied between different questions within the category and students expressed high readiness to take climate politics into account when voting $(\mathrm{M}=4.04, \mathrm{SD}=1.28, \mathrm{Mdn}=5, \mathrm{~N}=1585)$, and over half of the respondents reported to already doing so. Readiness for participating in organizational activity $(M=2.23$, $\mathrm{SD}=1.06, \mathrm{Mdn}=2, \mathrm{~N}=1585)$ and influencing through media $(\mathrm{M}=2.28, \mathrm{SD}=1.17, \mathrm{Mdn}=2$, $\mathrm{N}=1585$ ) received especially low scores. 
Table 1

Descriptives of the Different Questions within Sum Variable Social Activity

\begin{tabular}{|c|c|c|c|c|c|c|}
\hline \multicolumn{7}{|l|}{ Statistics } \\
\hline & & 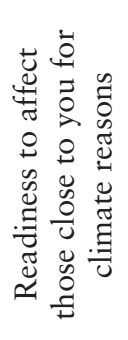 & 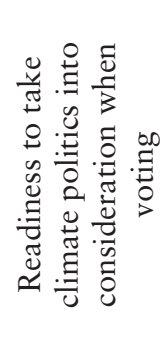 & 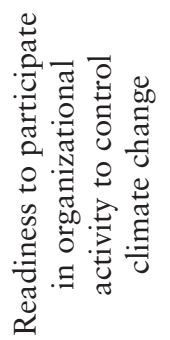 & 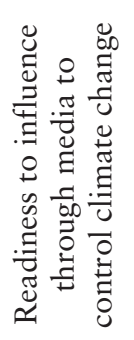 & 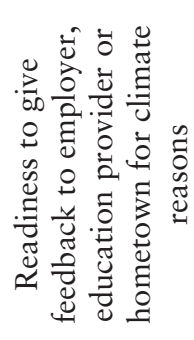 \\
\hline \multirow{2}{*}{$\mathrm{N}$} & Valid & 1585 & 1585 & 1585 & 1585 & 1585 \\
\hline & Missing & 0 & 0 & 0 & 0 & 0 \\
\hline Mean & & 3,1224 & 4,0353 & 2,2334 & 2,2839 & 2,7937 \\
\hline Median & & 3,0000 & 5,0000 & 2,0000 & 2,0000 & 3,0000 \\
\hline Mode & & 3,00 & 5,00 & 2,00 & 2,00 & 3,00 \\
\hline Std. deviation & & 1,35173 & 1,28069 & 1,05697 & 1,16511 & 1,14909 \\
\hline
\end{tabular}

It is important to take into account that, while there are more extreme views expressed in the open-ended questions, the quantitative analysis suggests that most participants did not belong to extreme ends of the spectrum in the sum variable of social activity.

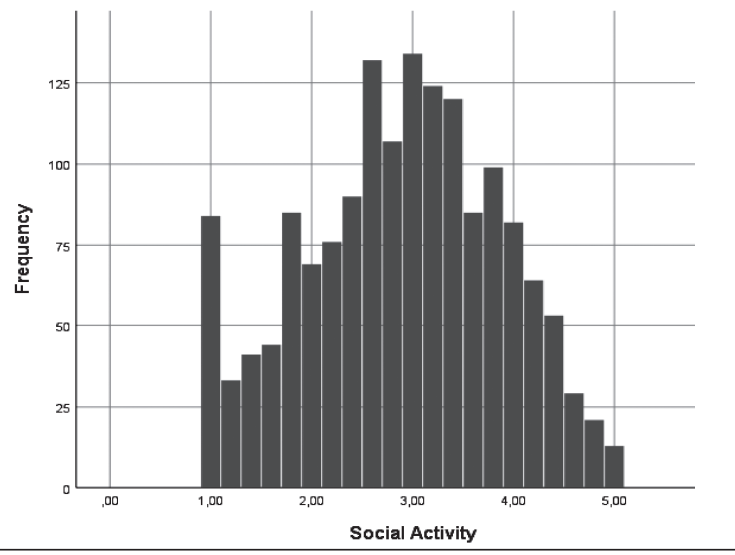

\begin{tabular}{|c|c|c|c|c|c|}
\hline \multicolumn{6}{|c|}{ Social Activity, stylised } \\
\hline & & Frequency & Percent & $\begin{array}{c}\text { Valid } \\
\text { Percent }\end{array}$ & $\begin{array}{c}\text { Cumulative } \\
\text { Percent }\end{array}$ \\
\hline \multirow[t]{6}{*}{ Valid } & Not at all ready & 158 & 10,0 & 10,0 & 10,0 \\
\hline & Not very ready & 364 & 23,0 & 23,0 & 32,9 \\
\hline & Quite ready & 617 & 38,9 & 38,9 & 71,9 \\
\hline & Very ready & 383 & 24,2 & 24,2 & 96,0 \\
\hline & I already do this & 63 & 4,0 & 4,0 & 100,0 \\
\hline & Total & 1585 & 100,0 & 100,0 & \\
\hline
\end{tabular}

Figure 1. The distribution of the student's readiness for climate actions in social activity as continuous data and stylized into ordinal data for easy comparison with the original scale of the questions 
From Figure 1, we can see that most respondents report moderate views regarding climate actions in social activity and only a small percentage of respondents belong to either end of the spectrum. There are, however, more people who were not at all ready for climate actions compared to those who already report doing a climate action in this category, and this can also be seen on the histogram.

Readiness (and non-readiness) for climate actions within social activity was explained by Emotional Expressions and Trustworthy Information, Individual Freedom, Societal Responsibility, and a Us Against the World-mindset. Different numbers of answers were given in each category, with Emotional Reasoning and Societal Responsibility containing the most responses.

Emotional Expressions contained expressions from the whole emotional scale, but the majority of the answers in this category expressed unwillingness to take part in social activities. The following emotional expressions were identified:

\section{Irritation}

Personally, the way media fusses over climate change is starting to annoy me a bit by bit more than to awaken me, and this easily causes an opposite response in reducing climate change ( $\mathrm{S} 135)$,

Disgust

This disgusting climate hysteria that is pushing from every direction has gone way too far! (S2),

Hypocrisy and contradicting actions

On top of this, many of today's most visible activists are in my opinion hypocrites, because they may e.g. preach against private motoring, while they themselves fly abroad several times a year (S36),

\section{Anxiety}

Climate change is probably one of the biggest problems in my lifetime. I experience constant climate anxiety and I try to do as much as I can. Other people's weaseling out gives me anxiety and I try to do everything I can to hammer in to their heads how big, terrible and scary things we are talking about here (S87),

Arrogance

I am used to people being stupid (S124),

Boredom resulting from getting enough from the subject

I don't understand why climate matters are constantly repeated in the media. I am already bored of the conversation - (S64),

Fear of getting stigmatized or criticized

I, myself, am afraid to talk about climate change because I fear that I will be labeled as a "watermelon" [a dismissive term used about environmentalists] (S119), 
Description of the general atmosphere and polarization of the conversation on the topic

Climate issues add on duality, the conversation lacks facts and only feelings are brought up in the form of a 16-year-old girl (S80),

Accusing others

We must condemn problems and harmful attitudes and behaviour around us loudly, so that a societal change in attitude is possible (S218),

Positive expressions

Active people should remember to approach the subject from a hopeful point of view, so that the message could reach as many people as possible and wouldn't make people feel guilty (S133).

Trustworthy Information contained expressions which insisted that all taken action should be based on facts. It consisted of answers expressing:

Lack of sufficient information

I would want to do more, but I don't really know how and where I could be active in my city (S48),

Stating out contradicting information

I have received so much contradicting views from researchers that I am not at all sure even on my own view about how catastrophic climate change is (S16),

Hope for objective and rational information

It is the job of scientists to bring objective knowledge to citizens, so that they can base their decisions on it (S58),

Information given by experts and not by people with political agendas or the media I would like to make sure that the information regarding climate action given by the media is truthful and not based on the market's demands (S138),

Hope on more knowledge on how to act

On the other hand, information helps people to make informed decisions and a lot of people don't probably know all the sides to climate change and environmental actions and this shows constantly as aged arguments (S130).

There were no comments where students stated that they had enough or too much information on the matter, but it is possible that students who felt this way, expressed their thoughts in the other categories.

Individual Freedom emphasized the individual's right to do what they want. The following expressions were identified:

People have the right to act independently

People have the right to do as they please. Freedom over all (S43),

People have the right and freedom to form their own opinions

I think we should respect everyone and their right to make their own decisions (S203), 
Personal reasons and life conditions

As a working person with a family, I don't have much time for any sort of activism (S59),

Personal choices without accusing others

I try to inspire those close to me to act in a climate-friendly way by having conversations with them and leading by example (S56),

Not wanting to impose

Everyone makes their own decisions themselves and I don't want to to push my way of life to other people (S5).

Societal Responsibility consisted of answers that perceived and contemplated the issue of climate change and acting on it on a societal level. The following expressions were identified:

Politicization

The subject has been strongly politicized (S71),

In practice, every political party has stupid climate politics (S39),

Individual's political actions in society

Climate actions are portrayed in how I vote (S97),

Legislation

The society should "force" us consumers to act in a more sensible way regarding climate! (S107),

I think the most important thing is to accomplish proper international contracts (S164),

Economics

Companies and large factories should be aware of their climate choices and these should be public (S65),

Environmental organisations are rarely supported financially - if we want to enhance the action of environmental organisations and get their goals realistic, financial support is absolutely needed (S89),

Energy production

In my opinion the best environmental action would be to build a nuclear power plant (S161),

Individual's responsibilities in the society

I think activity in societal matters and climate actions made by individuals are valuable and deserve more appreciation and attention. However; I believe that change should start from above (companies and government) (S91).

Us Against the World-mindset involved answers that considered Finland's role in climate change. The following expressions were identified: 
It doesn't matter what a Finnish person does

Climate change is such a big global problem that Finland or Finnish people alone do not have any impact on the big picture (S6),

Why should we as a nation take action when other countries do not

Questions regarding climate change should be tackled where problems begin: e.g. developing countries and China are downright indifferent to the issue. These are the emission giants whose actions should be intervened with before interfering in Finland's affairs, where things related to emissions are well (S57),

Only wanting to affect locally

I am not ready to do anything for the global climate but I am ready to a lot for our local environment (S3),

Finland can act as a role model and develop different kinds of solutions and competence regarding climate change

Finland should focus more on exporting know-how abroad, so that countries with high levels of pollution, could move faster towards a similar situation that has been already achieved in Finland (S103),

Us as equals in the world

Even though right now we have millions and millions of people living (and dying) in extreme poverty, it is possible to rise from there and I don't have any kind of sole right to my wealthy standard of living (S196).

The opportunities for social activity provided by the students consisted on intervening with actions of "climate-giant" countries, developing and exporting innovations and expertise, leading by example as an individual and as a nation, telling other people about climate actions and approaching them in a hopeful manner, receiving and distributing reliable information, making decisions and regulations on a societal level, providing economical support for environmental organizations, and affecting by personal actions.

\section{Discussion}

This paper aimed to find out university students' personal perceptions for social activity in a climate change context. From an individual's perspective, there are many levels to this issue: What I already do; What I should do; If and how I should try to influence others and whether it makes sense to try to affect at all. Considering the issue from Bildung perspective, that includes a notion of humanity directed towards a mode of life that is self-chosen and emancipated (Masschelein \& Ricken, 2003), even the rejection of the world is in compliance with the notion as freedom is in the core of Bildung (Reichenbach, 2003). However, when Bildung is considered from the perspective of human adaptivity, it needs to be viewed as human problem-solving (Pikkarainen, 2018).

The results of this research show that most of the respondents express moderate or moderately low readiness in social activity regarding climate actions. Less than a third $(28 \%)$ of respondents reported being very ready for social activity regarding climate 
change or being already active. A third (33\%) reported being not at all ready or not very ready for social activities, while the rest (39\%) reported moderate readiness. These results are similar to Besong and Holland's (2015) findings that many higher education learners do not take action to support their communities' sustainability and show unwillingness to develop community-based climate-action plans. Readiness (and non-readiness) for climate actions within social activity was explained by Emotional Expressions and Trustworthy Information, Individual Freedom, Societal Responsibility, and a Us Against the World-mindset.

In this research, high polarisation could be identified from the open-ended question. Many of those who answered it expressed that they were unready or unwilling to take action in climate matters. As this high polarisation can not be seen to the same extent when examining the respondents' readiness for climate action in the category of social activity quantitatively, it is possible that those, who hold moderate views and moderate readiness (the majority of respondents), have not responded to the open-ended questions to the same extent. As it is possible that people with extreme views more often voice their opinions, the views of the "quiet middle-man" often go unheard, even when most respondents would belong to this category.

The capability of recognizing the situations when it is better to rely on the judgment done by others is equally valuable as action on the grounds of own judgment (Saukkonen \& Räihä, 2018). Wals (2020) brings up the idea of capable citizens in the even playing field, remarking that the supposition is generally incorrect, and it can also be seen in this research. There were impressions that suggested that we do not all need to be active in the social playing field of climate change, but those who are active can inspire others to join. Many respondents explained their unreadiness for social activity by personal reasons or attributes. Personal characteristics can prevent some from taking action, for introverts being active in an organization can feel especially confrontational even if they were willing to take action.

Those who expressed moderate views in the open-ended questions mainly concentrated on describing the general atmosphere and culture of debate around climate change. The culture of debate was described as being polarized, depressive and volatile and this was often named as a hurdle that hinders the willingness to take action or even discuss the topic with others. The duality and polarization conveyed in these observations was also seen in our results. The following statements indicate this:

\section{This disgusting climate hysteria that is pushing from every direction has gone way too far! (S2) \\ Other people's weaseling out gives me anxiety and I try to do everything I can to hammer in to their heads how big, terrible and scary things we are talking about here. (S87)}

Contemporary societies are faced with the anxiety over the weakening of rational open discussion and public realm of debate, which causes disruption and confusion (Norman \& Barnett, 2020). Education needs to produce people who think critically and are able to synthesize diverse information regarding versatile situations in the world, which in practice means noting contradictory results and the toleration of compromises (Salonen \& Åhlberg, 2012). A change in the culture of debate is needed to encourage also those with low or moderate readiness to take part in social activities regarding 
climate actions, but we also need individuals who are ready and willing to take part in conversation even when it may be hard.

Inculpatory attitudes resulted in people deciding not to take action. As Norgaard (2006) suggests, people's aim is to manage unpleasant emotions and this can hinder participation in social movements. As climate change itself causes negative emotions (Hamilton, 2019; Pihkala, 2019; Smith \& Leiserowitz, 2012), what we don't need is even more negative emotions arising from the culture of the debate, that then needs to be managed, and can therefore further lower readiness to take social activity in matters regarding climate change. If people are bombarded with matters at scales that seem too broad to conquer, it causes them to tune out or downplay (Wals, 2020). According to Wals (2020), pessimism, hopelessness, helplessness, and inactivity regarding global challenges of sustainability are quite prevalent feelings. People commit themselves emotionally to their values and feel hurt if the values are thwarted (Salonen \& Konkka, 2015 ) and that is expressed as uncertainty towards future society and its values.

Hypocrisy and contradiction in speech and behaviour caused a lot of criticism from the respondents. In some cases, where someone tried to achieve changes in behaviour in others, or "put themselves on a pedestal" while still making questionable climate choices e.g., flying to a climate conference, this caused disapproval. However, it is natural and understandable that these kinds of feelings arise in response to contradictions in actions and speech; it seems like pointing out such cases may also be used as means to justify the lack of social activity in climate actions in one's own life.

Interestingly an "all-or-nothing"-attitude hindered people's readiness for social climate activity in two ways. It was seen as a loophole, or the reason to do nothing because of the impossibility of doing everything, as well as working as a reason for those who were socially active for feeling like they couldn't influence others because they themselves weren't perfect. People also reported that they had faced criticism and experienced belittling if they tried to do something positive for the climate e.g., eat vegan food. They did not succeed or live perfectly by all aspects. This would suggest that a lower threshold for climate activities is needed - a sort of grey area between the black and white, to get more people to do more things, even when not doing everything. People who try to change their own actions should not be required to have more advanced moral principles than the people who do not concern themselves (Schlottmann, 2012). It is possible to be an active citizen without extremism (Cantell, 2006). However, the study did suggest that many believe that individuals can affect climate change by leading by example and discussing the matter with others.

Lack of reliable and objective knowledge was often named as a reason for not being socially active in climate matters. Previous studies (Lorenzoni, Nicholson-Cole, \& Whitmarsh, 2007) have suggested that lack of knowledge and not trusting the information sources act as barriers in engaging with climate change. Our study suggests that reliable, researched and well justified information can support individuals in assessing their own views and building their big picture on climate change which again can affect if and how they take social action.

According to our study, university students feel that emotions and reasoning are often pitted against each other when discussing climate change. In our research, it seemed that emotional reasoning and reasoning based on researched information were often seen as the opposites of each other, and, furthermore, emotions were often seen to downplay the trustworthiness of the given information. It seems unlikely that these 
two, in reality, would have to be contradicting and could only exist without each other. However, it does seem that climate change being strongly politicized, commercialized, and being plentifully discussed in the media, can not only weaken student's trust in the information but also promote negative emotions such as irritation, disgust, and boredom. As previous studies suggest (Salama \& Aboukoura, 2018; Markowitz \& Shariff, 2012; Fredrickson, 2001), more positive climate communication and emotional appeals can be better in accomplishing long-lasting climate actions.

The US Against the World-mindset identified in our study is very similar to the findings of Norgaard's (2006) study from Norway. Finland and Norway are neighbouring countries with similar sized populations. In both studies, belittling one's own nation's actions due to its small size and shifting blame and responsibility to bigger countries were reported. As Norgaard (2006) also suggested, this may be due to both a sense of powerlessness as well as getting off the hook. By contrast, there were also many respondents who were proud of Finland's actions and believed Finland could play a vital role in climate change through exporting technology, innovations, and expertise. Locality and taking care of Finland's nature and local climate were important to some people who were not willing to take action on a global level. Intervening with the actions of "climate-giant" countries was also seen as a means to affect climate change through social activity.

When regarding the solutions to problems such as climate change, and without withholding the responsibility of an individual, it is crucial to acknowledge the key role of the actors above individuals especially the government (Schlottmann, 2012). In order to achieve sustainability, change is needed both at the individual and societal level (Salonen \& Åhlberg, 2012). Particularly in our research, it was indicated that more societal and governmental level decisions are needed to both insure and encourage more climate considering actions. Economical support for environmental organizations was also named as a way to affect climate change on a societal level.

As not all of us can, or want to be, like Greta Thunberg, lower profile activities should not be seen with disapproval. This research provides valuable information on the reasons behind why some people are indifferent towards climate change or express unreadiness and/or unwillingness to take social action. Individuals cannot usually decipher the misinformation and distortions they may discover, and therefore societal learning deteriorates (Norman \& Barnett, 2020). Our results suggest that climate matters do not only affect emotions and are not only reacted on emotionally, but students require facts and well justified reasoning - a change in the culture of debate, as well as societallevel decision making and individual freedom. Many students also strongly contextualize themselves as Finnish, and this plays a definite role in their social activities regarding climate change. The students considered hypocrisy and contradictions in actions and words especially obnoxious.

It annoys me to see made-up women who otherwise live like they don't give a damn about the climate tweeting \#savetheamazon \#naturefirst. (S82)

The limitations of this study include the culture-bound nature of the topic, as was showcased through the Us Against the World-mindset. Our research is also only limited to the views of university students in a medium size Finnish city, and more research is needed on what hinders taking action for people of other ages and from other cultures and contexts. There is also a possibility that individual interpretation has affected our 
results, exemplified by the term "Quite ready" presented in the Likert-scale questions can represent different things to different people.

\section{Conclusion}

The readiness for social activity in climate actions is moderately low in students from the University of Oulu. There are several barriers that need to be broken to lower the threshold to engage in social climate activity. These include, but are not restricted to, change in the culture of debate; provision of researched and objective knowledge, and abstention from accusing or belittling others. However, it is important that shortcomings are allowed in both directions - explaining one's own lack of action should not solely be based on criticizing some contradicting actions in others.

As the majority of respondents report moderate readiness for climate activities, it is especially important to create an atmosphere where taking action feels comfortable and non-threatening to those on the fence. Even though taking action may feel especially difficult, respondents suggest multiple ways to affect climate action. If we as a society are not able to change how we talk about climate change and each other, we risk leaving lots of potential unused. More research is needed to understand why there is a difference between the readiness of men and women in taking action in climate matters.

\section{References}

Anspach, N., \& Draguljić, G. (2019). Effective advocacy: The psychological mechanisms of environmental issue framing. Environmental Politics, 28(4), 615-63. doi: 10.1080/09644016.2019.1565468

Besong, F., \& Holland, C. (2015). The dispositions, abilities and behaviours (DAB) framework for profiling learners' sustainability competencies in higher education. Journal of Teacher Education for Sustainability, 17(1), 5-22.

Bonnett, M. (2012). Environmental concern, moral education and our place in nature. Journal of Moral Education, 41(3), 285-300. doi: 10.1080/03057240.2012.691643

Cantell, H. (2006). From environmental awareness to responsibility: Challenges and possibilities. In Tani, S. (Ed.), Sustainable development through education. Proceedings of the international conference on environmental education (pp. 155-168). Research Report 268. Helsinki: University of Helsinki.

DSDG (n.d.). Division for sustainable development goals. Sustainable development goals knowledge platform, DESA, United Nations. Retrieved from https://sustainable development.un.org/about

Elo, S., \& Kyngäs, H. (2008). The qualitative content analysis process. Journal of Advanced Nursing, 62(1), 107-115. doi: 10.1111/j.1365-2648.2007.04569.x

Feinberg, M., \& Willer, R. (2011). Apocalypse soon? Dire messages reduce belief in global warming by contradicting just-world beliefs. Psychological Science, 22(1), 34-38. doi: 10.1177/0956797610391911

Fredrickson, B. (2001). The role of positive emotions in Positive Psychology: The broaden and build theory of positive emotions. American Psychologist, 56(3), 218-226. doi: 10.1037/0003-066X.56.3.218

Gardiner, S. M. (2006). A perfect moral storm: Climate change, intergenerational ethics and the problem of moral corruption. Environmental Values, 15(3), 397-413. 
Greasley, P. (2008). Quantitative data analysis using SPSS: An introduction for health \& social science. Maidenhead: Open University Press/McGraw-Hill Education.

Hamilton, J. (2019) Emotions, reflexivity and the long haul: What we do about how we feel about climate change. In Hogget, P. (Ed.), Climate psychology: On indifference to disaster (pp. 153-175). Cham: Palgrave Macmillan. doi: 10.1007/978-3-03011741-2

Hines, J. M., Hungerford, H. R., \& Tomera, A. N. (1987). Analysis and synthesis of research on responsible pro-environmental behavior: A meta-analysis. The Journal of Environmental Education, 18(2), 1-8. doi: 10.1080/00958964.1987.9943482

Holsman, R. H. (2001). The politics of environmental education. The Journal of Environmental Education, 32(2), 4-7. doi: 10.1080/00958960109599131

Horlacher, R. (2016). The educated subject and the German concept of Bildung. A comparative cultural history [E-book]. New York, NY: Routledge.

Häikiö, L. (2012). Kestävä kehitys. Utopia kehittyvästä ja kestävästä kansalaisten yhteiskunnasta [Sustainable development. The utopia of a developing and sustainable citizens' society]. In Helne, T., \& Silvasti, T. (Eds.), Yhteyksien kirja. Etappeja ekososiaalisen hyvinvoinnin polulla [The book of connections. Waypoints on the path of eco-social well-being] (pp. 150-157). Helsinki: Kelan tutkimusosasto.

Incropera, F. P. (2015). Climate change: A wicked problem - complexity and uncertainty at the intersection of science, economics, politics and human behaviour. Cambridge: Cambridge University Press. doi: 10.1017/CBO9781316266274

Johnston, E., Rasmusson, X., Foyil, B., \& Shopland, P. (2017). Witnesses to transformation: Family member experiences providing individualized music to their relatives with dementia. Cogent Education, 4(1), 1-12. doi: 10.1080/2331186X.2017. 1362888

Keinonen, T., Palmberg, I., Kukkonen, J., Yli-Panula, E., Persson, C., \& Vilkonsis, R. (2016). Higher education students' perceptions of environmental issues and media coverage. Discourse and Communication for Sustainable Education, 7(1), 5-22. doi: 10.1515/dcse-2016-0001

Kivelä, A., Siljander, P., \& Sutinen, A. (2012). Between Bildung and Growth: Connection and controversies. In Siljander, P., Kivelä, A., \& Sutinen, A. (Eds.), Theories of Bildung and Growth. Connections and controversies between Continental Educational Thinking and American Pragmatism (pp. 303-312). Rotterdam: Sense Publishers. doi: 10.1007/978-94-6209-031-6

Klöckner, C. A., Matthies, E., \& Hunecke, M. (2003). Problems of operationalizing habits and integrating habits in normative decision-making models. Journal of Applied Social Psychology, 33(2), 396-417. doi: 10.1111/j.1559-1816.2003. tb01902.x

Kollmuss, A., \& Agyeman, J. (2002). Mind the gap: Why do people act environmentally and what are the barriers to pro-environmental behavior? Environmental Education Research, 8(3), 239-260. doi:10.1080/13504620220145401

Kronlid, D. O., \& Öhman, J. (2013). An environmental ethical conceptual framework for research on sustainability and environmental education. Environmental Education Research, 19(1), 21-44. doi: 10.1080/13504622.2012.687043

LeDoux, J. (2012). Rethinking the emotional brain. Neuron, 73(4), 653-676. doi: 10.1016/j.neuron.2012.02.004 
Leiserowitz, A. (2006). Climate change risk perception and policy preferences: The role of affect imagery, and values. Climatic Change, 77(1), 45-72. doi: 10.1007/s10584006-9059-9

Lorenzoni, I., Nicholson-Cole, S., \& Whitmarsh, L. (2007). Barriers perceived to engaging with climate change among the UK public and their policy implications. Global Environmental Change, 17(3-4), 445-459. doi: 10.1016/j.gloenvcha.2007.01.004

Markowitz, E., \& Shariff, A. (2012). Climate change and moral judgement. Nature Climate Change, 2(4), 243-247. doi: 10.1038/nclimate1378

Masschelein, J., \& Ricken, N. (2003). Do we (still) need the concept of Bildung? Educational Philosophy and Theory, 35(2), 139-154. doi: 10.1111/1469-5812.00015

Massey, D. (2004). Geographies of responsibility. Geografiska Annaler [Geografiska Annaler: Series B, Human Geography], 86B(1), 5-18.

Metsämuuronen, J. (2011). Tutkimuksen tekemisen perusteet ihmistieteissä: Tutkijalaitos [The basis for research in humanities: Research institute] $\left(4^{\text {th }}\right.$ ed.). Helsinki: International Methelp.

Norgaard, K. (2006). People want to protect themselves a little bit: Emotions, denial, and social movement nonparticipation. Sociological Inquiry, 76(3), 372-396.

Norgaard, K. (2011). Living in denial: Climate change, emotions, and everyday life. Cambridge, Mass.: The MIT Press.

Norman, J., \& Barnett, R. (2020). Introduction. Steps to ecologies for learning and practice. In Barnett, R., \& Jackson, N. (Eds.), Ecologies for learning and practice. Emerging ideas, sightings, and possibilities (pp. 1-15). Oxon \& New York: Routledge.

Ojala, M. (2013a). Emotional awareness: On the importance of including emotional aspects in education for sustainable development (ESD). Journal of Education for Sustainable Development, 7(2), 167-182. doi: 10.1177/0973408214526488

Ojala, M. (2013b). Coping with climate change among adolescents: Implications for subjective well-being and environmental engagement. Sustainability, 5(5), 21912209. doi: 10.3390/su5052191

Pihkala, P. (2017a). Environmental education after sustainability: Hope in the midst of tragedy. Global Discourse: An interdisciplinary journal of current affairs, 7(1), 109-127. doi: 10.1080/23269995.2017.1300412

Pihkala, P. (2017b). Kuinka käsitellä maailman ongelmia? Traagisuus ja toivo ympäristökasvatuksessa [How to deal with the problems of the world? The tragedy and hope in environmental education]. Ainedidaktiikka [Subject Didactics], 1(1), 215. doi: 10.23988/ad.v1i1.65801

Pihkala, P. (2019). Climate anxiety. Retrieved from https://mieli.fi/en/raportit/climateanxiety

Pikkarainen, E. (2012). Signs of reality. The idea of general Bildung by J. A. Comenius. In Siljander, P., Kivelä, A., \& Sutinen, A. (Eds.), Theories of Building and Growth. Connections and controversies between Continental Educational Thinking and American Pragmatism [E-book] (pp. 19-29). Rotterdam: Sense Publishers.

Pikkarainen, E. (2018). Adaption, learning, Bildung: Discussion with edu- and biosemiotics. Sign Systems Studies, 46(4), 435-451.

Postma, D. W., \& Smeyers, P. (2012). Like a swallow, moving forward in circles: On the future dimension of environmental care and education. Journal of Moral Education, 41(3), 399-412. doi: 10.1080/03057240.2012.691637 
Reichenbach, R. (2002). On irritation and transformation: A-teleological Bildung and its significance for the democratic form of living. Journal of Philosophy of Education, 36(3), 409-419. doi: 10.1111/1467-9752.00284

Reichenbach, R. (2003). Beyond sovereignty: The twofold subversion of Bildung. Educational Philosophy and Theory, 35(2), 201-209. doi: 10.1111/1469-5812.00019

Salama S., \& Aboukoura K. (2018). Role of emotions in climate change communication. In Leal Filho, W., Manolas, E., Azul, A., Azeiteiro, U., \& McGhie, H. (Eds.), Handbook of climate change communication, 1. climate change management (pp. 137-150). Cham, Springer.

Salonen, A. O. (2019). Is sustainability about education for life satisfaction? Sustainability, 11(3), 611-612. 10.3390/su11030612

Salonen, A. O., \& Konkka, J. (2015). An ecosocial approach to well-being: A solution to the wicked problems in the era of Anthropocene. Foro de Educación [Education forum], 13(19), 19-34. doi: 10.14516/fde.2015.013.019.002

Salonen, A. O., \& Åhlberg, M. K. (2012). The path towards planetary responsibility expanding the domain of human responsibility is a fundamental goal for lifelong learning in a high-consumption society. Journal of Sustainable Development, 5(8), 13-26. doi: 10.5539/jsd.v5n8p13

Saukkonen, S., \& Räihä, P. (2018). Autonomisuuteen kasvattaminen on vastuutonta, mutta myös mahdotonta [Raising for autonomy is irresponsible but also impossible]. In Saukkonen, S., \& Moilanen, P. (Eds.), Vastuuseen kasvaminen ja kasvattaminen [Growing and raising into responsibility] [E-book] (pp. 79-95). Jyväskylä: Suomen kasvatustieteellinen seura.

Sauvé, L. (2009). Being here together. In McKenzie, M., Hart, P., Bai, H., \& Jickling, B. (Eds.), Fields of green: Restoring culture, environment, and education (pp. 325335). Cresskill, NJ: Hampton Press.

Schlottmann, C. (2012). Conceptual challenges for environmental education. Advocacy, autonomy, implicit education \& values. New York, NY: Peter Lang.

Smith, N., \& Leiserowitz, A. (2012). The rise of global warming skepticism: Exploring affective image associations in the United States over time. Risk Analysis, 32(6), 1021-1032. doi: 10.1111/j.1539-6924.2012.01801.x

Smith, N., \& Leiserowitz, A. (2014) The role of emotion in global warming policy support and opposition. Risk Analysis, 34(5), 937-948. doi: 10.1111/risa.12140

Taylor, A. L., Dessai, S., \& Bruine de Bruin, W. (2014). Public perception of climate risk and adaptation in the UK: A review of the literature. Climate Risk Management, 4-5, 1-16. doi: 10.1016/j.crm.2014.09.001

Tolppanen, S., Claudelin, A., \& Kang, J. (2020). Pre-service teachers' knowledge and perceptions of the impact of mitigative climate actions and their willingness to act. Research in Science Education. doi: 10.1007/s11165-020-09921-1

UNESCO. (2002). Education for sustainability, from Rio to Johannesburg: Lessons learnt from a decade of commitment. Retrieved from https://unesdoc.unesco.org/ ark:/48223/pf0000127100

United Nations. (2012). Framework convention on climate change. Retrieved from https://unfccc.int/resource/docs/2012/cop18/eng/08a02.pdf\#page=17

Vilkka, H. (2017). Tutki ja kehitä (4. uudistettu painos) [Research and develop, $4^{\text {th }} \mathrm{ed}$.]. Jyväskylä: PS-kustannus. 
Volanen, M. V. (2012). Sivistyksen muuttuneet historialliset ja teoriahistorialliset olosuhteet [The changed historical and theory. Historical circumstances of Bildung] Kasvatus [The Finnish Journal of Education], 43(5), 534-539.

Wals, A. E. J. (2020). Sustainability-oriented ecologies of learning. A response to systemic global dysfunction. In Barnett, R., \& Jackson, N. (Eds.), Ecologies for learning and practice. Emerging ideas, sightings, and possibilities (pp. 61-78). Oxon \& New York: Routledge.

Weintrobe, S. (Ed.). (2013). Engaging with climate change: Psychoanalytic and interdisciplinary perspectives. New York: Routledge.

Yang, Z. J., \& Kahlor, L. (2013). What, me worry? The role of affect in information seeking and avoidance. Science Communication, 35(2), 189-212. doi: 10.1177/ 1075547012441873

Correspondence related to this paper should be addressed to Sari Harmoinen, University of Oulu, Finland, Education Dean, Faculty of Educational Science and Teacher Education. Email: Sari.Harmoinen@oulu.fi 